\title{
Effectiveness of Full (Comprehensive) Preparatory Units for College Study Abroad Field Trips
}

\author{
Mark R. M. Otten ${ }^{1}$ \\ ${ }^{1}$ Biology Department, University of Cincinnati, Blue Ash College, USA \\ Correspondence: Mark R. M. Otten, Biology Department, University of Cincinnati, Blue Ash College, 9555 \\ Plainfield Road, Blue Ash, OH, 45236, USA.
}

Received: April 12, 2018

Accepted: May 9, 2018 Online Published: May 15, 2018

doi:10.5539/jel.v7n4p40

URL: https://doi.org/10.5539/jel.v7n4p40

\begin{abstract}
Research shows that students are likely to experience novelty (unfamiliarity) at field trip locations, resulting in extended, unproductive disorientation and inhibition of learning. Carefully-planned preparatory units, delivered prior to the field trip experience, have been shown to mitigate the negative effects of novelty. Anonymous online surveys and written responses to critical thinking questions were used to assess the effect of full (comprehensive) pre-field trip preparatory units on measures potentially influenced by novelty during a 25-day college study abroad program. Survey responses indicate that full preparatory units did not significantly affect student perception of readiness or location familiarity. While few statistically-significant differences were detected, data suggests that full preparatory units probably enhanced student satisfaction with the field trip experience and fostered better performance on critical thinking assessments. These findings support the conclusion that full preparatory units were, on the whole, more beneficial to learning during study abroad field trips than were minimal preparatory units. Findings also suggest that college students may not suffer the negative effects of novelty as intensely as younger students and that the physical size and complexity of the field trip location may reduce student confidence in navigating the location and slow student completion of on-location tasks.
\end{abstract}

Keywords: field trips, novelty, preparatory units, study abroad

\section{Introduction}

The positive impacts of field trips on student learning have been well documented (e.g., Falk \& Dierking, 1997; Garner \& Gallo, 2005; Hurley, 2006; reviewed by Behrendt \& Franklin, 2014). Notably, Lei (2010) identified numerous field trip benefits as perceived by both students and teachers, including increasing student self-confidence and self-efficacy, fostering student-generated interest, lowering communication barriers between students and teachers, and enhancing critical thinking and synthesis of information. In a survey of undergraduate students, graduate students, and faculty at the University of Western Australia, Rahman and Spafford (2009) found that while all respondents agreed that field trips are an important component to university education, they differed in their perception of value place. Faculty emphasized the importance of experiential learning as a constituent of a unified and integrated curriculum; while students emphasized improvement in retention and future value to career attainment and professional development (Rahman \& Spafford, 2009). Owen (2016) reported that students in a college freshman biology course found on-campus nature walks to be significantly more engaging than traditional lecture, without loss of content mastery. For $11^{\text {th }}$ grade students in Nigeria, Hamilton-Ekeke (2007) found that students receiving ecology-based content during a field trip performed significantly better on post instruction tests than students receiving the same content in traditional lecture format. In an attempt to document what students learn during a field trip, Greene, Kisida, and Bowen (2014) surveyed 10912 students and 489 teachers from 129 high schools following a guided tour of the Crystal Bridges Museum of American Art in northwest Arkansas. They found that students retained $79 \%-88 \%$ of content, cultural message, and context of artwork up to three weeks post-trip, with students from rural and low-income schools benefiting most. Indeed, Greene et al. (2014) concluded that “. . . enriching field trips contribute to the development of students into civilized young men and women who possess more knowledge about art, have stronger critical thinking skills, exhibit increased historical empathy, display higher levels of tolerance, and have a greater taste for consuming art and culture" (pp.80). For a field study abroad program in Costa Rica, Houser, Brannstrom, Quiring, and Lemmons (2011) found that while participants and non-participants (those not 
participating in the field study abroad program) performed equally well on exams before and immediately following the program, field trip participants scored significantly higher on an exam administered six weeks following return to the United States. Field study abroad program participants attributed their improved test performance to greater interaction with course content. The authors speculated that extensive development of social connections, both among students and between students and teachers, during the field trip likely contributed to higher test scores (Houser et al., 2011).

The effectiveness of field trips is due in part to the close interspersion of formal and non-formal learning encompassed in the typical structure of the field trip experience. (This paper follows Eshach's [2007] classification of learning during field trips as non-formal rather than informal.) The basic structure of the school field trip, pre-trip preparation $\rightarrow$ field trip $\rightarrow$ follow-up activities, appears in the teaching literature as early as the 1890s (McMurray, 1895). In McMurray's (1895) organization, both pre-trip preparation and follow-up activities occur in the classroom and constitute formal learning, while the field trip itself primarily constitutes non-formal learning (Rudmann, 1994). Wellington (1990) notes that non-formal educational settings, such as interactive museums, often create an environment that is more conducive to discovery learning as the less rigid, informal setting imposes fewer restrictions on student behavior and thinking. Wellington (1990) suggests that cognitive, psychomotor, and affective learning are all important aspects of the total educational experience and that formal education in science overemphasizes the cognitive component of learning to the detriment of the psychomotor and the affective. The typical field trip sequence of formal learning $\rightarrow$ non-formal learning $\rightarrow$ formal learning juxtaposes psychomotor and affective learning with cognitive learning.

Like McMurray (1895), Orion (1993) models the structure of the total field trip experience as three independent, but inter-supportive parts: preparatory unit $\rightarrow$ field trip unit $\rightarrow$ summary unit. (For consistency, Orion's [1993] unit terminology is adopted throughout the remainder of this paper.) Orion (1993) envisions field trip structure as sequentially guiding students to connect concrete knowledge developed during the preparatory unit to deeper understanding of abstract concepts via critical thinking, analysis, and synthesis during summary unit activities. The actual field trip event functions as the interactive, experiential, non-formal bridge between the concrete and the abstract. Orion (1993) argues that a successful field trip must include all three of these unit elements.

The close and sequential integration of formal class work with non-formal discovery learning, however, means that any event or factor that impacts planned activities or disrupts the connection among field trip components can detract from learning. One of these factors is the novelty (unfamiliarity) of a location to trip participants. Falk, Martin, and Balling (1978) and Martin, Falk, and Balling (1981) showed that students in a novel field trip setting initially engage in undirected site exploration and non-task social interaction while building familiarization to the new environment. Time and attention expended in response to novelty, however, reduce attentiveness toward objectives and hinders knowledge acquisition. Falk and Balling (1982) later showed that learning on a field trip was at least partly dependent on intensity of the setting novelty. Delving into the source of novelty, Orion and Hofstein (1991) identified three interacting components: psychological factors, geographical factors, and cognitive factors that define the "novelty space" students experience when confronted by a new learning environment. Elkins and Elkins (2007) subsequently included social factors to encompass the effect of a novel environment on student social interactions. These and related research have documented or investigated the negative effect of novelty space on student learning (Orion \& Hofstein, 1994; Cotton \& Cotton, 2009; Xie \& Garner, 2009).

Suggested guidelines and recommendations for effective field trips consistently emphasize the importance of preparatory units to the ultimate success of the experience (e.g., Rudmann, 1994; Scarce, 1997; Hurley, 2006; Bamberger \& Tal, 2008). The purposes or objectives of the preparatory unit are varied, ranging from the logistic to the pedagogical. Preparatory units are expected to specify the "nuts and bolts" of the field trip event by detailing trip itinerary (McLoughlin, 2004), reviewing safety and health parameters (Nabors, Edwards, \& Murray, 2009), identifying behavioral expectations (Behrendt \& Franklin, 2014), informing students of specific field trip learning objectives (Wong \& Wong, 2008), making students aware of the conditions they are likely to encounter (Scarce, 1997; Hurley, 2006), and tying field trip objectives to broader curricular learning outcomes (McLoughlin, 2004). Cognitively, preparatory units should use a variety of concrete orientation and learning activities designed to build foundational knowledge about the field trip topic, to minimize novelty space, and to improve learning (Orion, 1993). Gennaro (1981) reports that $8^{\text {th }}$ grade students who participated in pre-visit instructions showed greater overall knowledge acquisition from the field trip site. Similarly, Kubota \& Olstad (1991) found that cognitive learning and on-task behavior of $6^{\text {th }}$ grade students improved when field trips were preceded by novelty-reducing activities. Bamberger \& Tal (2008) recommend that preparatory units include 
psychological and geographic components, as well as cognitive components, to mitigate the several sources of site novelty that detract from learning.

\section{Study Objectives and Predictions}

Researchers from diverse disciplines have incorporated field trips into short-term college study abroad programs (e.g., Herbold \& Geagan, 2002; Smieja, D’Ambruoso, \& Richman, 2010; Palmer \& Menard-Warwick, 2012; Womble, De'Armond, \& Babb, 2014). College students who study abroad, however, are likely to encounter a number of barriers to learning not similarly faced by students participating in field trips closer to home. Factors such as anxiety/homesickness (Nichols, Rothenberg, Moshi, \& Tetlof, 2013), unfamiliar signage, feelings of awe or stress (Burns, 1991), interactions with native residents and other visitors, conflicts with classmates in a foreign environment (Bodycott, 2015), and physical fatigue (Nichols et al., 2013) may contribute to novelty space. The pedagogy of field trips suggests that the impediments associated with study abroad novelty space can be minimized through well planned, comprehensive preparatory units before the field trip excursion (Rudmann, 1994; Cotton \& Cotton, 2009).

The objective of this study was to evaluate the effectiveness of full (comprehensive) pre-field trip preparatory units on learning during a short-term college study abroad program. To do so, two field trips were preceded by a minimal preparatory unit and two field trips were preceded by a full preparatory unit. The effectiveness of full preparatory units was assessed through (1) surveys of student perception of readiness and location familiarity, (2) surveys of student satisfaction with the field trip experience, and (3) student responses to blog entry prompts and essay questions gauging critical thinking. If full preparatory units facilitate learning during field trips, then study abroad students receiving detailed, location-specific preparatory units will report higher perception of field trip readiness, report higher location familiarity, report greater satisfaction with the field trip experience, and score higher on responses to blog entry prompts and essay questions demonstrating or testing critical thinking.

\section{Methods}

The effectiveness of full pre-field trip preparatory units on learning was assessed during a study abroad program from the University of Cincinnati, Blue Ash College (UCBA) to various locations in England from June 12 to July 6, 2011. Students participating in the program enrolled in one or both of two courses: English 289 Evolution and Revolution: The Beatles, the 60's, and Cultural Change (hereafter referred to as the "Beatles course") and Biology 296 - Evolution: History and Processes (hereafter referred to as the "Evolution course"). Professor Michael Roos of the UCBA English Department taught the Beatles course, while I taught the Evolution course. Each course included classroom instruction completed at Harlaxton College, Harlaxton, Lincolnshire, and three field trips. There was a total of six field trips embedded in the program.

All students participating in the study abroad program attended all six field trips, whether they were enrolled in the course with which a specific field trip was associated or not. Field trips, given chronologically, were distributed throughout the 25-day program but tended to be clustered based on geographic location.

- June 14, 2011: Down House (home of Charles Darwin), Downe, Kent - Evolution course

- June 15, 2011: The British Musical Experience, $\mathrm{O}_{2}$ Arena, London - Beatles course

- June 22, 2011: Sedgwick Museum, Cambridge University, Cambridge - Evolution course

- June 28, 2011: The Beatles Story museum/Beatles bus tour, Liverpool - Beatles course

- July 2, 2011: The Beatles Walk, London - Beatles course

- July 3, 2011: Natural History Museum, London - Evolution course

The first four field trips were selected for inclusion in this study. While the final two field trips were excluded from the study, they remained part of the study abroad program and received full preparatory units.

Level of preparatory unit (minimal or full) was assigned to field trips such that each course featured one minimal preparatory unit and one full preparatory unit, and such that one of the two field trips conducted during the first week of the program was preceded by a minimal preparatory unit while the other was preceded by a full preparatory unit. This was done to avoid any potential time effect from full preparatory units occurring on adjacent days early in the program. A random number generator was used to assign a full preparatory unit to one of the field trips, while the remaining field trips were assigned preparatory unit levels following the restrictions described above. The Down House field trip was randomly selected to be preceded by a full preparatory unit. Subsequently, the British Musical Experience field trip was assigned a minimal preparatory unit, the Sedgwick Museum field trip was assigned a minimal preparatory unit, and The Beatles Story museum/Beatles bus tour field trip was assigned a full preparatory unit. 


\subsection{Field Trip Preparatory Units}

Field trip preparatory units were presented to students no more than two days prior to the actual field trip. The content of minimal preparatory units was presented in association with other coursework during a single class meeting. The content of full preparatory units was presented in association with other coursework during class meetings on two consecutive days. Professor Roos presented the preparatory units to the Beatles course, while I presented the preparatory units to the Evolution course.

Minimal preparatory units included a description of field trip objectives, a description of the field trip location, and a discussion of the course assignments and activities to be completed in association with the field trip. Students were encouraged to ask questions about any aspect of the upcoming field trip experience. Complete, detailed answers were provided to all questions, including questions beyond the scope of the information formally presented as part of the minimal preparation. While answering such questions may have expanded the intended breadth of the minimal preparatory unit, providing students with as much information as requested was judged to contribute to a more satisfying and productive field trip. Providing complete, detailed responses to student questions probably did not expanded the scope of the minimal preparatory units to the point of impacting this study.

The content of full preparatory units was more variable than the content of minimal preparatory units, being more specifically tailored to the attributes of the field trip location and objectives. Full preparatory units included a description of field trip objectives, a description of the field trip location, a discussion of the course assignments and activities to be completed during the field trip, a description of the route to the field trip location with points of interest along the way, a timetable of arrival and departure, specific linkage between the course-related content of the field trip and associated lecture content, examination of the location website (if available), interactive maps and floor plans with specific reference to trip location content, virtual tours, associated videos, and online reviews.

\subsection{Field Trip Summary Units}

In addition to a preparatory unit and the actual site unit, Orion's (1993) model of field trip structure stresses the importance of a summary unit immediately following each field trip. The summary unit uses post-trip discussion, reflection, and guided syntheses to encourage students to form connections among concrete facts and as a lead-in to higher cognitive concepts (Orion, 1993). All UCBA study abroad program field trips were followed by group discussions intended to frame the observations and activities completed at the location within the larger context of course material, to give students an opportunity to provide feedback, and discuss potential improvements to the field trip. While the scope of post-trip discussions varied somewhat depending on student experiences at the location, every effort was made to keep summary units as consistent as possible. This was done to reduce the effect of summary unit discussion on student perceptions of preparatory unit efficacy.

\subsection{Surveys to Assess the Effectiveness of Preparatory Units}

The effectiveness of full preparatory units on student perception of field trip readiness, location familiarity, and student satisfaction with the field trip experience was assessed using anonymous, online, 13-statement surveys administered following each field trip. Student responses were categorized along a Likert-style scale as: $1=$ "Strongly Disagree", 2 = "Disagree", 3 = "Neither Agree nor Disagree", 4 "Agree", and 5 = "Strongly Agree". Statements were scored independently and both the Beatles course and the Evolution course used the same survey statements. Students enrolled in both courses completed online surveys following field trips for the Evolution course only.

The effect of full preparatory units on student perceptions of field trip readiness and on location familiarity was assessed using responses to the following six survey statements:

1) The objectives of the field trip were clear.

2) I knew what to expect before arriving at the field trip location.

3) I felt confident in my ability to navigate through the field trip location before arrival.

4) I was able to focus on class activities very soon after arriving at the field trip location.

5) I completed the required course activities to my satisfaction.

6) Pre-field trip instructions and activities helped me get the most out of the visit.

The effect of full preparatory units on student satisfaction with the field trip experience was assessed using responses to the following seven survey statements: 
7) I was excited about visiting the field trip location before arrival.

8) My experience at the field trip location was better than I expected.

9) Required class activities were relevant to the field trip and to the objectives of the visit.

10) I learned or discovered something unexpected at the field trip location.

11) Activities and discussion following the field trip positively contributed to my appreciation of the field trip location.

12) The field trip supported the learning objectives of the course.

13) I enjoyed the visit to the field trip location.

\subsection{Prompted Blog Entries and Critical Thinking Essay Questions}

For the Beatles course, the effectiveness of full preparatory units on critical thinking was assessed by evaluating student responses to blog entry prompts. Students participating in the Beatles course maintained an online blog documenting their cognitive, emotional, and physical experiences during the study abroad program. Blog entry prompts were written by Professor Roos.

Minimal Preparation Unit - Blog Entry Prompt

In 750-1000 words, write a blog entry based upon what you learned at the British Musical Experience (BME). Focus on following one particular way in which rock music either influenced a particular social, cultural, and/or political event or trend in the 1960s or, conversely, was influenced by a particular social, cultural, and/or political event or trend in the 1960s. Illustrate your points with at least six examples from what you saw on display at the BME. Also reflect on what you learned in the experience, how you were changed in any way by what you saw. Feel free to supplement your text with photos and/or video.

Full Preparation Unit - Blog Entry Prompt

In 750 - 1000 words, write a blog entry based upon your experience of our tour of the Beatles sites and Museum in Liverpool. Focus primarily on what you learned about the early lives of the Beatles, how they were influenced by their childhood environment, schooling, parents, friends, and other experiences. Illustrate your points with at least six examples from what you saw in Liverpool. Also reflect on what you learned in the experience, how you were changed in any way by what you saw. Feel free to supplement your text with photos and/or video.

Written responses to blog entry prompts by students enrolled in the Beatles course were evaluated by Professor Roos using the following rubric:

Points Criteria

5 Points Detailed reflections on the experience, connecting the details of experience to thoughts and feelings (i.e. more than a run-down of the day).

4 Points Detailed but only on the experience or only on thoughts and feelings. Little connection between experience $\&$ thoughts and feelings.

3 Points Adequately detailed, but with only minimal connection between experience \& thoughts and feelings.

2 Points Few if any details from the experience, with very little connection between experience \& thoughts and feelings.

1 Point No details or connections between experiences and thoughts and feelings.

For the Evolution course, the effectiveness of full preparatory units on critical thinking was assessed by evaluating student responses to four essay questions located on course tests. Two essay questions, one following the minimal preparatory unit and one following the full preparatory unit, were centered on aspects of the content (e.g., ideas, information, and objects) of the field trip, while the other two essay questions centered on physical aspects of the field trip location.

\section{Minimal Preparatory Unit - Content-Centered Critical Thinking Essay Question}

The Sedgwick Museum includes reconstructions of the desks maintained by botanist Robert Brown, petrologist Alfred Harker, and petrologist Sally Gibson. Read the accompanying placards and carefully examine the organization and content of these desks. In particular, take note of the specimens, notebooks, 
and books present on the desks. How did the work of Charles Darwin (both before and after the voyage of the Beagle) influence or inform the subsequent research of these scientists? Give specific examples to support your explanation.

Minimal Preparatory Unit - Location-Centered Critical Thinking Essay Question

The Sedgwick Museum houses millions of specimens, only a small fraction of which are actually on display. Based just on what you observed while walking through the Sedgwick Museum, speculate on why it is organized the way it is and why the curators selected the specimens they did. Describe specific specimens and display placements to support your speculation. (Hint: think about the various functions or purposes of museums.)

Full Preparatory Unit - Content-Centered Critical Thinking Essay Question

Visit Darwin's Study at some point during your exploration of Down House.

a. Identify three instruments or devices in the Study. Describe each instrument or device and explain specifically how Darwin would have used it for compiling the content of "On the Origin of Species". For example, one of the devices is a spool of string. Darwin would have used this string to bind or anchor pigeon specimens and to suspend plant samples (either from his greenhouse or donated by colleagues) for close examination and comparison. You may not use the spool of string as one of the instruments or devices you describe.

b. Notice that Darwin kept a fair number of books in the Study for easy access and reference. Name two books (with authors) that Darwin would have likely kept handy while preparing "On the Origin of Species". Why would Darwin want to have these particular books easily accessible?

Full Preparatory Unit - Location-Centered Critical Thinking Essay Question

As you walk through the grounds of Down House, pay attention to the semi-rural landscape of the location. This landscape is most noticeable in the Great Meadow/Sandwalk area. Recall from "The Reluctant Mr. Darwin" that Charles never felt truly comfortable in London. Speculate on how the semi-rural landscape of Down House provided an environment conducive for Darwin's drafting of "On the Origin of Species". Identify specific conditions at Down House and in London to support your speculation.

Responses to critical thinking essay questions by students enrolled in the Evolution course were evaluated using the following rubric:

Points Criteria

5 Points Response is factually accurate and includes specific, relevant information that is clearly discussed in proper context. Response displays exceptional depth of understanding of the history of life on Earth, evolution theory, and/or Darwin's life, thinking, and writing.

4 Points Response is factually accurate and includes specific, relevant information that is clearly discussed in proper context. Response displays appropriate, but not exceptional, depth of understanding of the history of life on Earth, evolution theory, and/or Darwin's life, thinking, and writing.

3 Points Response is factually accurate includes specific, relevant information. Information not always clearly discussed in proper context. Response displays appropriate, but not exceptional, depth of understanding of the history of life on Earth, evolution theory, and/or Darwin's life, thinking, and writing.

2 Points Response is factually accurate but lacks specific, relevant information. Information not always clearly discussed in proper context. Response may or may not display appropriate depth of understanding of the history of life on Earth, evolution theory, and/or Darwin's life, thinking, and writing.

1 Point Response is not factually accurate or lacks specific, relevant information. Information is not always clearly discussed in proper context. Response does not display appropriate depth of understanding of the history of life on Earth, evolution theory, and/or Darwin's life, thinking, and writing.

\subsection{Data Analysis}

A two-tailed $t$-test was used to determine whether mean Likert scores assigned by students for all survey statements were significantly different between the Beatles course and the Evolution course. This approach was 
used to determine whether student responses to survey statements could be pooled across courses and within preparatory unit level (minimal or full). Mean Likert scores were considered to be significantly different, thus prohibit response pooling, if $p \leq 0.05$.

Fisher's Exact Test was used to determine whether the distribution of student responses among Likert categories was significantly different between minimal preparatory unit field trips and full preparatory unit field trips for each survey statement. Of the total responses recorded, none (0\%) were "Strongly Disagree" and only the four categories garnering responses ("Disagree", "Neither Agree nor Disagree", "Agree", and "Strongly Agree") were included in analyses. Response distributions among the four response categories were considered to be significantly different if $p \leq 0.05$. For each survey statement, the number of students in both courses responding "Disagree" were combined, the number of students in both courses responding "Neither Agree nor Disagree" were combined, the number of students in both courses responding "Agree" were combined, and the number of students in both courses responding "Strongly Agree" were combined.

Two-tailed paired $t$-tests were used to determine whether mean rubric scores earned by students on prompted blog entries and critical thinking essay questions were significantly different between minimal preparatory unit field trips and full preparatory unit field trips. This approach was used to determine whether full preparatory units significantly increased student scores on prompted blog entries and critical thinking essay questions. Mean student scores were considered to be significantly different if $p \leq 0.05$.

\section{Results}

Twenty students participated in the UCBA study abroad program in England in 2011. Nine students were enrolled only in the Beatles course, four students were enrolled only in the Evolution course, and seven students were enrolled in both courses. Thus, a total of 16 students were enrolled in the Beatles course, and a total of 11 students were enrolled in the Evolution course.

\subsection{Surveys to Assess Student Perception of Field Trip Readiness, Location Familiarity, and Student Satisfaction with the Field Trip Experience}

All nine students enrolled only in the Beatles course were given the opportunity to respond to surveys following field trips associated with this course. All four students enrolled only in the Evolution Course were given the opportunity to respond to surveys following field trips associated with this course. Of the seven students enrolled in both courses, one student completed surveys following field trips associated with the Beatles course while six students completed surveys following field trips associated with the Evolution course. No student completed surveys following field trips associated with both courses. This was done to ensure that each student completed no more than one survey following each type of preparatory unit and to equalize the number of student respondents per course (10 students each).

Eight of 10 students in the Beatles course completed the survey following the minimal preparatory unit field trip to the British Musical Experience, while nine of 10 students in the Evolution course completed the survey following the minimal preparatory unit field trip to the Sedgwick Museum. Ten of 10 students in the Beatles course completed the survey following the full preparatory unit field trip to The Beatles Story museum/Beatles bus tour, while 10 of 10 students in the Evolution course completed the survey following the full preparatory unit field trip to Down House. Thus, 37 of a possible 40 surveys (92.5\%) were completed, 18 for the Beatles course and 19 for the Evolution course.

A total of 481 response scores were recorded for surveys across both courses (13 statements per survey, 37 completed surveys). Of the responses provided, 471 out of 481 (97.9\%) were distributed in the top three Likert scale categories. Student responses were distributed among the categories as follows:

$$
\text { Strongly Disagree }=0 / 481=0 \% \text { of responses }
$$

Disagree $=10 / 481(5$ Beatles course, 5 Evolution course $)=2.1 \%$ of responses

Neither Agree nor Disagree $=49 / 481(29$ Beatles course, 20 Evolution course $)=10.2 \%$ of responses

Agree $=210 / 481(96$ Beatles course, 114 Evolution course $)=43.7 \%$ of responses

Strongly Agree $=212 / 481(104$ Beatles course, 108 Evolution course $)=44.1 \%$ of responses

Mean Likert score assigned by students in the Beatles course was $4.278\left(n=234, s^{2}=0.579\right)$ while mean Likert score assigned by students in the Evolution course was $4.316\left(n=247, s^{2}=0.501\right)$. Mean Likert scores assigned by students were not significantly different between the Beatles course and the Evolution course $(t=0.57, p=$ $0.571, d f=472)$. Nonsignificant difference in assignment of Likert scores to survey statements permitted pooling of student responses by statement across the two courses. 
The distribution of student responses to survey statements $1-6$ suggests that full pre-trip preparatory units did not significantly affect student perception of readiness and location familiarity (Table 1). While a greater percentage of students responded "Strongly Agree" to survey statements documenting perception of clarity of field trip objectives (Statement 1), awareness of what to expect before arrival (Statement 2), ability to focus on field trip activities (Statement 4), and positive effect on the visit (Statement 6) following full preparatory field trips, most were not substantially higher.

Contrary to expectations, a smaller percentage of students responded "Strongly Agree" to survey statements documenting confidence in ability to navigate the field trip location (Statement 3) and in satisfaction in completing course activities (Statement 5) following full preparatory unit field trips (Table 1). While the distribution of student responses was not significantly different between minimal preparatory unit field trips and full preparatory unit field trips for either statement, the $p$ value associated with the distribution of student responses to Statement 3 is fairly low.

Table 1. Comparison of distribution of pooled responses to survey statements assessing student perception of field trip readiness and location familiarity relative to level of the pre-trip preparatory unit. Response distributions were considered significantly different if $p \leq 0.05$, Fisher's Exact Test. Likert categories: $\mathrm{D}=$ "Disagree", NAD = "Neither Agree nor Disagree", A = "Agree", and SA = "Strongly Agree". No responses were "Strongly Disagree".

\begin{tabular}{|c|c|c|c|c|c|}
\hline \multirow{2}{*}{$\begin{array}{l}\text { Survey Statement } \\
\text { Preparatory Unit Level }\end{array}$} & \multicolumn{4}{|c|}{ Likert Category } & \multirow{2}{*}{$\begin{array}{l}\text { Fisher's Exact Test } \\
\text { Result }\end{array}$} \\
\hline & $\mathrm{D}(\%)$ & NAD (\%) & $\mathrm{A}(\%)$ & SA (\%) & \\
\hline \multicolumn{6}{|c|}{ 1. The objectives of the field trip were clear. } \\
\hline Minimal Preparation & 0 & $1(6 \%)$ & $10(59 \%)$ & $6(35 \%)$ & \\
\hline Full Preparation & $1(5 \%)$ & 0 & $7(35 \%)$ & $12(60 \%)$ & $p=0.155$ \\
\hline \multicolumn{6}{|c|}{ 2. I knew what to expect before arriving at the field trip location. } \\
\hline Minimal Preparation & $1(6 \%)$ & $6(35 \%)$ & $7(41 \%)$ & $3(18 \%)$ & \\
\hline Full Preparation & $2(10 \%)$ & $2(10 \%)$ & $10(50 \%)$ & $6(30 \%)$ & $p=0.359$ \\
\hline \multicolumn{6}{|c|}{ 3. I felt confident in my ability to navigate through the field trip location before arrival. } \\
\hline Minimal Preparation & 0 & $2(12 \%)$ & $5(29 \%)$ & $10(59 \%)$ & \\
\hline Full Preparation & 0 & $2(10 \%)$ & $12(60 \%)$ & $6(30 \%)$ & $p=0.182$ \\
\hline \multicolumn{6}{|c|}{ 4. I was able to focus on class activities very soon after arriving at the field trip location. } \\
\hline Minimal Preparation & 0 & $3(18 \%)$ & $9(53 \%)$ & $5(29 \%)$ & \\
\hline Full Preparation & $1(5 \%)$ & $3(15 \%)$ & $7(35 \%$ & $9(45 \%)$ & $p=0.549$ \\
\hline \multicolumn{6}{|c|}{ 5. I completed the required course activities to my satisfaction. } \\
\hline Minimal Preparation & 0 & 0 & $9(53 \%)$ & $8(47 \%)$ & \\
\hline Full Preparation & $1(5 \%)$ & $1(5 \%)$ & $11(55 \%)$ & $7(35 \%)$ & $p=0.925$ \\
\hline \multicolumn{6}{|c|}{ 6. Pre-field trip instructions and activities helped me get the most out of the visit. } \\
\hline Minimal Preparation & 0 & $3(18 \%)$ & $11(65 \%)$ & $3(18 \%)$ & \\
\hline Full Preparation & $1(5 \%)$ & $4(20 \%)$ & $8(40 \%)$ & $7(35 \%)$ & $p=0.344$ \\
\hline
\end{tabular}

The distribution of responses to survey statements $7-13$ indicates that full pre-trip preparatory units likely enhanced student satisfaction with the field trip experience (Table 2). A greater percentage of students responded "Strongly Agree" to all seven statements documenting satisfaction with the field trip experience following full preparatory unit field trips as compared to minimal preparatory unit field trips. Of these, however, the distribution of student responses was significantly different only for "My experience at the field trip location was better than I expected" (Statement 8) and "The field trip supported the learning objectives of the course" (Statement 12) (Table 2). Significant improvement in the distribution of student responses to these statements may reflect a more complete understanding of the field trip timeline/route, previous exposure to the field trip location via online resource, and a clearer idea of curricular alignment of the field trip as provided by full preparatory units. 
Level of pre-field trip preparation did not appear to influence student perception of whether activities and discussion following the field trip positively contributed to appreciation of the field trip location (Statement 11, Table 2). This outcome is not unexpected for two reasons. First, post-field trip summary units were limited to tying field trip activities to course content, and, unlike the preparatory units, did not vary among field trips. Second, the link between preparatory unit and summary unit may not have been recognized by students. While Orion (1993) argues that summary units are an integral part of the entire field trip strategy, their function promoting connections among concrete facts and abstract concepts is not always readily apparent. As such, the slightly higher positive perception of students following full preparatory unit field trips may be due to the comprehensive nature of preparatory units themselves rather than any discussion or activities following the field trip.

Table 2. Comparison of distribution of pooled responses to survey statements assessing student satisfaction with the field trip experience relative to level of the pre-trip preparatory unit. Response distributions were considered significantly different if $p \leq 0.05$, Fisher's Exact Test. Likert categories: $\mathrm{D}=$ "Disagree", NAD = "Neither Agree nor Disagree", A = "Agree", and SA = "Strongly Agree". No responses were "Strongly Disagree".

\begin{tabular}{|c|c|c|c|c|c|}
\hline \multirow{2}{*}{$\begin{array}{l}\text { Survey Statement } \\
\text { Preparatory Unit Level }\end{array}$} & \multicolumn{4}{|c|}{ Likert Category } & \multirow{2}{*}{$\begin{array}{l}\text { Fisher's Exact Test } \\
\text { Result }\end{array}$} \\
\hline & $\mathrm{D}(\%)$ & NAD (\%) & $\mathrm{A}(\%)$ & SA $(\%)$ & \\
\hline \multicolumn{6}{|c|}{ 7. I was excited about visiting the field trip location before arrival. } \\
\hline Minimal Preparation & 0 & $3(18 \%)$ & $8(47 \%)$ & $6(35 \%)$ & \\
\hline Full Preparation & $1(5 \%)$ & $2(10 \%)$ & $4(20 \%)$ & $13(65 \%)$ & $p=0.160$ \\
\hline \multicolumn{6}{|c|}{ 8. My experience at the field trip location was better than I expected. } \\
\hline Minimal Preparation & 0 & $5(29 \%)$ & $4(25 \%)$ & $8(47 \%)$ & \\
\hline Full Preparation & 0 & 0 & $7(35 \%)$ & $13(65 \%)$ & $p=0.031$ \\
\hline \multicolumn{6}{|c|}{ 9. Required class activities were relevant to the field trip and to the objectives of the visit. } \\
\hline Minimal Preparation & 0 & $1(6 \%)$ & $11(65 \%)$ & $5(29 \%)$ & \\
\hline Full Preparation & 0 & $1(5 \%)$ & $9(45 \%)$ & $10(50 \%)$ & $p=0.503$ \\
\hline \multicolumn{6}{|c|}{ 10. I learned or discovered something unexpected at the field trip location. } \\
\hline Minimal Preparation & 0 & $3(18 \%)$ & $7(41 \%)$ & $7(41 \%)$ & \\
\hline Full Preparation & 0 & 0 & $10(50 \%)$ & $10(50 \%)$ & $p=0.253$ \\
\hline \multicolumn{6}{|c|}{ 11. Activities and discussion following the field trip positively contributed to my appreciation of the field trip location. } \\
\hline Minimal Preparation & $1(6 \%)$ & $3(18 \%)$ & $9(53 \%)$ & $4(34 \%)$ & \\
\hline Full Preparation & $1(5 \%)$ & $3(15 \%)$ & $9(45 \%)$ & $7(35 \%)$ & $p=0.907$ \\
\hline \multicolumn{6}{|c|}{ 12. The field trip supported the learning objectives of the course. } \\
\hline Minimal Preparation & 0 & $1(6 \%)$ & $11(65 \%)$ & $5(29 \%)$ & \\
\hline Full Preparation & 0 & 0 & $6(30 \%)$ & $14(70 \%)$ & $p=0.029$ \\
\hline \multicolumn{6}{|c|}{ 13. I enjoyed the visit to the field trip location. } \\
\hline Minimal Preparation & 0 & 0 & $7(41 \%)$ & $10(59 \%)$ & \\
\hline Full Preparation & 0 & 0 & $2(10 \%)$ & $18(80 \%)$ & $p=0.052$ \\
\hline
\end{tabular}

\subsection{Prompted Blog Entries and Critical Thinking Essay Questions}

While no significant differences were detected, data indicate that, overall, students performed better on assessments testing critical thinking following full preparatory unit field trips than following minimal preparatory unit field trips (Table 3).

All 16 students enrolled in the Beatles course completed blog entries following the minimal preparatory unit field trip and following the full preparatory unit field trip. The mean score for blog entries following the full preparatory unit field trip was notably higher than the mean score for blog entries following the minimal preparatory unit field trip. While the difference between these means was not significant $(p=0.055)$ the associated $p$ value was quite low (Table 3). 
Ten of 11 students enrolled in the Evolution course completed essay questions following the minimal preparatory unit field trip and following the full preparatory unit field trip. One student did not complete essay questions following the minimal preparatory unit field trip. Essay scores for this student were not included in the analysis. Mean score for responses to the content-centered critical thinking essay question was slightly lower following the full preparatory unit field trip (Table 3). Mean score for responses to the location-centered critical thinking essay question was notably higher following the full preparatory unit field trip. While the difference between these means was not significant $(p=0.082)$ the associated $p$ value was fairly low (Table 3 ).

Table 3. Comparison of mean $(s, n)$ student score (1-5 scale) on prompted blog entries and critical thinking essay questions relative to level of the pre-field trip preparatory unit. Score means were considered significantly different if $p \leq 0.05$, paired $t$-test. Test statistic $(t)$, degrees of freedom $(d f)$, and probability $(p)$ reported for each comparison.

\begin{tabular}{|c|c|c|c|c|}
\hline \multirow[b]{2}{*}{ Course } & \multirow[b]{2}{*}{ Assessment } & \multicolumn{2}{|c|}{ Mean Student Score $(s, n)$} & \multirow[b]{2}{*}{$t, d f, p$} \\
\hline & & Minimal Preparation & Full Preparation & \\
\hline Beatles & Blog Entry & $\begin{array}{l}4.25 \\
s=0.683 \\
n=16\end{array}$ & $\begin{array}{l}4.56 \\
s=0.661 \\
n=16\end{array}$ & $\begin{array}{l}t=2.08 \\
d f=15 \\
p=0.055\end{array}$ \\
\hline Evolution - Content & Essay Question & $\begin{array}{l}3.5 \\
s=0.850 \\
n=10\end{array}$ & $\begin{array}{l}3.4 \\
s=0.843 \\
n=10\end{array}$ & $\begin{array}{l}t=0.29 \\
d f=9 \\
p=0.778\end{array}$ \\
\hline Evolution - Location & Essay Question & $\begin{array}{l}3.5 \\
s=0.527 \\
n=10\end{array}$ & $\begin{array}{l}3.8 \\
s=0.789 \\
n=10\end{array}$ & $\begin{array}{l}t=1.96 \\
d f=9 \\
p=0.082\end{array}$ \\
\hline
\end{tabular}

\section{Discussion}

Perceptions of field trip readiness and location familiarity are of particular interest as they are likely to be influenced by site novelty and the degree to which that novelty may interfere with learning. For this study, survey statements $1-6$ were written partly to evaluate the success of full preparatory units on shrinking novelty space. Student responses to these statements suggest that increasing the level of pre-field trip preparation did not significantly reduce site novelty. Note, however, that a substantial proportion of responses to these statements were "Agree" or "Strongly Agree" following both minimal preparatory unit field trips and full preparatory unit field trips (Table 1). In their study on the effect of field trips on attitudes, behaviors and learning among 196 primary school students, Falk and Balling (1982) found that older students spent more time on-task during a field trip to a nature center than did younger students visiting a similar location. This suggests that the negative effects of novelty space may diminish with age. In addition, Anderson and Lucas (1997) found that performance by $8^{\text {th }}$ grade Australian students on post-test assessments was highest for students who had previously visited the field trip location and had also participated in teacher-directed pre-trip activities. Interpreting student responses to survey statements 1-6 relative to the findings of Falk and Balling (1982) and Anderson and Lucas (1997), I propose that college-age students, benefitting from natural maturation and previous $\mathrm{K}-12$ field trip experience, may not face substantial site novelty, regardless of level of preparation. If this is so, even short, superficial preparatory units may be sufficient to minimize the negative effects of novelty space on college-age learners.

Differences in the physical extent, spatial layout, and environmental diversity among field trip locations may account for lower student confidence in navigate the field trip location (Statement 3) and slightly lower student satisfaction in completing course activities (Statement 5) following full preparatory unit field trips. The two field trip locations preceded by minimal preparatory units (British Musical Experience and Sedgwick Museum) were comparatively small, entirely indoor, and fairly homogeneous. The organizations of these locations allowed students to move rapidly among different parts of the museum, to quickly find and interact with faculty and other students, and to easily locate specific displays. Conversely, the two field trip locations preceded by full preparatory units (The Beatles Story museum/Beatles bus tour and Down House), were comparatively large, contained both indoor and outdoor components, and were environmentally diverse. The organizations of these locations required students to traverse longer distances, allowed students to become physically separated, made it more difficult for students to find faculty when necessary, and may have impeded student ability to locate 
specific content. While it is unclear whether additional preparation would have alleviated some of these potential difficulties, the distribution of student responses to other survey statements does not indicate heightened novelty at the larger, more heterogeneous field trip sites. Students may simply have perceived time limitation more acutely at these locations, underscoring the importance of balancing guided tasks with the opportunity for discovery/orientation on field trips (Rudmann, 1994).

Relative to the objective of this study to evaluate the effectiveness of full (comprehensive) pre-field trip preparatory units on student learning, employing field trip locations of variable physical extent and environmental diversity was probably not optimal. A more effective design for this objective would have been to use different student cohorts at exactly the same field trip locations, or to select field trip locations of approximately equal physical size and environmental diversity for visitation by a single student cohort. While variation in the characteristics of field trip locations and the assignment of the locations to preparatory unit level are recognized as limitations of the study, these limitations were unavoidable. Assignment of field trip locations to preparatory unit level was made to avoid possible time effect on student responses (see Methods). This effect was viewed as potentially more problematic than an environmental setting effect. Further, the overriding objective of the program was to provide students with the most cohesive, memorable, and educationally meaningful study abroad experience possible. The field trip locations selected and the order in which the field trips were employed best fit the criteria for meeting that objective.

While data do not show a statistically significant effect of full preparatory units on student satisfaction, a greater percentage of students responded "Strongly Agree" to all seven survey statements assessing this measure following full preparatory unit field trips. This evidence indicates a positive relationship between preparatory unit level and satisfaction with the field trip experience. The effect of pre-field trip preparatory units on student satisfaction has not been well documented. However, student responses collected during this study are broadly consistent with Wong and Wong (2008) who found that student perceptions of the effectiveness of pre-field trip activities were associated with overall student satisfaction and student perception of learning. Wong and Wong (2008) compared student responses to survey questions following field trips accompanying one of three courses offered by Hong Kong Polytechnic University, with each field trip directed by a different faculty leader. While Wong and Wong (2008) did not intentionally vary the quality of field trip preparatory units, differences in leader experience likely resulted in asymmetric preparation, with the most experienced leader providing the most thorough preparatory unit. The preparatory unit delivered by the most experienced leader subsequently garnered the highest student perception of effectiveness (Wong \& Wong, 2008).

The finding that students performed better on prompted blog entries and on location-centered critical thinking questions following field trips preceded by a full preparatory unit is consistent with previous research (Gennaro, 1981; Kubota \& Olstad, 1991; Anderson \& Lucas, 1997; also reviewed by DeWitt \& Storksdieck, 2008). Student performance on content-centered critical thinking questions, however, was nearly identical between minimal and full preparatory unit field trips. The proximate explanation for this outcome is unclear. Students may have found the two-part construction of the content-centered essay question more challenging or may have had difficulty recalling the requested content. Additionally, the structure and composition of the full preparatory unit employed may not have adequately prepared students to respond to the content-centered essay question given. In the design of the full preparatory unit for the Evolution course, more attention was paid to those properties of the field trip event thought to influence site novelty most substantially. As a result, greater emphasis was placed on the temporal, spatial, and physical aspects of the field trip (e.g. departure time, time spent at the location, route to the location, ground plans, maps, and virtual tours) and less emphasis on developing associations between location content and other course content. Emphasis on the spatio-physical aspects of the field trip may have better readied students to respond effectively to location-centered essay questions than to content-centered essay questions.

The number of U.S. college students participating in study abroad has increased from almost 206000 in 20042005 to over 325300 in 2015-2016 (Institute of International Education, 2018). Many study abroad programs will include one or more field trips (excursions) in support of course content. As such, information on the effectiveness and usefulness of pre-field trip preparatory units is potentially valuable to faculty and staff leading study abroad. The findings presented here are based on the survey responses and written essays of 20 students collected during a 25-day study abroad program, so must be viewed with some caution. While further research is needed to verify these findings, the data indicate that increasing the content and scope of pre-field trip preparatory units did not affect field trip readiness or location familiarity in college-age students, but probably enhanced student satisfaction with the field trip experience and fostered better performance on critical thinking assessments. Several factors, which were not assessed in this study but which might affect student learning, 
should be considered during study abroad field trip planning. In particular, the baseline susceptibility of college-age students to environmental novelty and the effect of field trip location size/complexity on student ability to complete tasks deserve additional attention or investigation.

\section{Acknowledgements}

I am indebted to Sarah Cummins-Sebree and Robin Lightner for timely discussions and indispensable assistance with study design and data analysis. Thanks to Angel Anorga, Brad Mallory, Amber Peplow, Scott Tremain, and Deb Trotta for early encouragement and to an anonymous reviewer for valuable comments and suggestions. Special thanks to the students who participated in this study and with whom I shared many enjoyable hours during study abroad. Finally, my sincerest gratitude to Mike Roos; not only for assisting in this study, but also for being a supportive colleague and a true friend. Without him this study could not have been completed.

\section{References}

Anderson, D., \& Lucas, K. B. (1997). The effectiveness of orienting students to the physical features of a science museum prior to visitation. Research in Science Education, 27, 485-495. https://doi.org/10.1007/BF02461476

Bamberger, Y, \& Tal, T. (2008). Multiple outcomes of class visits to natural history museums: The student's view. Journal of Science Education Technology, 17, 274-284. https://doi.org/10.1007/s10956-008-9097-3

Behrendt, M., \& Franklin, T. (2014). A review of research on school field trips and their value in education. International Journal of Environmental and Science Education, 9, 235-245.

Bodycott, P. (2015). Intragroup conflict during study abroad. Journal of International Students, 5, 244-259.

Burns, R. B. (1991). Study and stress among first year overseas students in an Australian University. Higher Education Research and Development, 10, 61-77. https://doi.org/10.1080/0729436910100106

Cotton, D. R. E., \& Cotton, P. A. (2009). Field biology experiences of undergraduate students: the impact of novelty space. Journal of Biological Education, 43, 169-174. https://doi.org/10.1080/00219266.2009.9656178

DeWitt, J., \& Storksdieck, M. (2008). A short review of field trips: key finding from the past and implications for the future. Visitor Studies, 11, 181-197. https://doi.org/10.1080/10645570802355562

Elkins, J. T., \& Elkins, N. M. L. (2007). Teaching geology in the field: Significant geoscience concept gains in entirely field-based introductory geology courses. Journal of Geoscience Education, 55, 126-132. https://doi.org/10.5408/1089-9995-55.2.126

Eshach, H. (2007). Bridging in-school and out-of-school learning: Formal, non-formal, and informal education. Journal of Science Education and Technology, 16, 171-190. https://doi.org/10.1007/s10956-006-9027-1

Falk, J. H., \& Balling, J. D. (1982). The field trip milieu: Learning and behavior as a function of contextual events. Journal of Education Research, 76, 22-28. https://doi.org/10.1080/00220671.1982.10885418

Falk, J. H., \& Dierking, L. D. (1997). School field trips: Assessing their long-term impact. Curator, 40, 211-218. https://doi.org/10.1111/j.2151-6952.1997.tb01304.x

Falk, J. H., Martin, W. W., \& Balling, J. D. (1978). The novel field trip phenomenon: Adjustment to novel settings interferes with task learning. Journal of Research in Science Teaching, 15, 127-134. https://doi.org/10.1002/tea.3660150207

Garner, L. C., \& Gallo, M. A. (2005). Field trips and their effect on student achievement and attitudes: A comparison of physical versus virtual field trips to the Indian River Lagoon. Journal of College Science Teaching, 34(5), 14-17.

Gennaro, E. A. (1981). The effectiveness of using pre-visit instructional material on learning for a museum field trip experience. Journal of Research in Science Education, 18, 275-279. https://doi.org/10.1002/tea.3660180312

Greene, J, P., Kisida, B., \& Bowen, D. H. (2014). The educational value of field trips: Taking students to an art museum improves critical thinking skills, and more. Education Next, 14(1), 79-86.

Hamilton-Ekeke, J-T. (2007). Relative effectiveness of expository and field trip methods of teaching on student's achievement in ecology. International Journal of Science Education, 29, 1869-1889. https://doi.org/10.1080/09500690601101664 
Herbold, N., \& Geagan, K. (2002). Study abroad: Foodways and nutrition in the traditional Mediterranean diet. Journal of Nutrition Education and Behavior, 34, 231-232. https://doi.org/10.1016/S1499-4046(06)60098-5

Houser, C., Brannstrom, C., Quiring, S. M., \& Lemmons, K. K. (2011). Study abroad field trip improves performance through engagement and new social networks. Journal of Geography in Higher Education, 35, 513-528. https://doi.org/10.1080/03098265.2010.551655

Hurley, M. M. (2006). Field trips as cognitive motivators for high level science learning. The American Biology Teacher, 68(6), e61-e66. https://doi.org/10.1662/0002-7685(2006)68[61:FTACMF]2.0.CO;2

Institute of International Education. (2018). Student profile. Retrieved April 11, 2018, from https://www.iie.org/Research-and-Insights/Open-Doors/Data/US-Study-Abroad/Student-Profile

Kubota, C., \& Olstad, R. (1991). Effects of novelty-reducing preparation on exploratory behavior and cognitive learning in a science museum setting. Journal of Research in Science Teaching, 28, 225-234. https://doi.org/10.1002/tea.3660280304

Lei, S. A. (2010). Field trips in college biology and ecology courses: Revisiting benefits and drawbacks. Journal of Instructional Psychology, 37, 42-48.

Martin, W. W., Falk, J. H., \& Balling, J. D. (1981). Environmental effects on learning: The outdoor field trip. Science Education, 65, 301-309. https://doi.org/10.1002/sce.3730650309

McLoughlin, A. S. (2004). Engineering active and effective field trips. Clearing House, 77, 160-163. https://doi.org/10.3200/TCHS.77.4.160-163

McMurray, C. A. (1895). Special Method in Geography for Third and Fourth Grade (2nd ed.). Bloomington, IL: Public School Publishing.

Nabors, M. L., Edwards, L. C., \& Murray, R. K. (2009). Making the case for field trips: What research tells us and what site coordinators have to say. Education, 129, 661-667.

Nichols, S. Y, Rothenberg, N. J., Moshi, L., \& Tetlof, M. (2013). International service learning: Students' personal challenges and intercultural competence. Journal of Higher Education Outreach and Engagement, 17(4), 97-124.

Orion, N. (1993). A model for the development and implementation of field trips as an integral part of the science curriculum. School Science and Mathematics, 93, 325-331. https://doi.org/10.1111/j.1949-8594.1993.tb12254.x

Orion, N., \& Hofstein, A. (1991). Factors which influence learning ability during a scientific field trip in a natural environment. Proceedings of the Annual Convention of the National Association for Research in Science Teaching, Fontana, IL.

Orion, N., \& Hofstein, A. (1994). Factors that influence learning during a scientific field trip in a natural environment. Journal of Research in Science Teaching, 31, 1097-1119. https://doi.org/10.1002/tea.3660311005

Owen, P. (2016). Nature walks as a tool for stimulating learning outside of the classroom. The Journal for Research and Practice in Teaching, 1, 1-11.

Palmer, D. K., \& Menard-Warwick, J. (2012). Short-term study abroad for Texas preservice teachers: On the road from empathy to critical awareness. Multicultural Education, 19(3), 17-26.

Rahman, T., \& Spafford, H. (2009). Value of field trips for student learning in the biological sciences. In Teaching and Learning for Global Graduates. Proceedings of the 18th Annual Teaching Learning Forum, 29-30, January, 2009. Perth: Curtin University of Technology.

Rudmann, C. L. (1994). A review of the use and implementation of science field trips. School Science and Mathematics, 94, 138-141. https://doi.org/10.1111/j.1949-8594.1994.tb15640.x

Scarce, R. (1997). Field trips as short-term experiential education. Teaching Sociology, 25, 219-226. https://doi.org/10.2307/1319398

Smieja, J. A., D’Ambruoso, G. E., and Richman, R. M. (2010). Art and chemistry: Designing a study abroad course. Journal of Chemical Education, 87, 1085-1088. https://doi.org/10.1021/ed900033x

Wellington, J. (1990). Formal and informal learning in science: The role of interactive science centres. Physics Education, 25, 247-252. https://doi.org/10.1088/0031-9120/25/5/307 
Womble, L., De'Armond, D., \& Babb, J. (2014). A model for designing faculty-led study abroad programs in the business curriculum. Academy of Educational Leadership Journal, 18(3), 93-110.

Wong, A., \& Wong, S. (2008). Useful practices for organizing a field trip that enhances learning. Journal of Teaching in Travel \& Tourism, 8, 241-259. https://doi.org/10.1080/15313220802714539

Xie, P. F., \& Garner, K. (2009). An analysis of students' photos of the novelty space on a field trip. Journal of Teaching in Travel and Tourism, 9, 176-192. https://doi.org/10.1080/15313220903379240

\section{Copyrights}

Copyright for this article is retained by the author, with first publication rights granted to the journal.

This is an open-access article distributed under the terms and conditions of the Creative Commons Attribution license (http://creativecommons.org/licenses/by/4.0/). 